\title{
Utilização da cama de frango em meio de cultivo de Bacillus thuringiensis var. israelensis Berliner para o controle de Aedes aegypti Linnaeus
}

\author{
Use of poultry litter as culture medium of Bacillus thuringiensis var. \\ israelensis Berliner for control of Aedes aegypti Linnaeus
}

\author{
André Luiz de Almeida Melo, ${ }^{1, *}$, Carlos Eduardo Sanchuki ${ }^{2}$, Adenise Lorenci \\ Woiciechowski $^{1}$, Vanete Thomaz-Soccol ${ }^{1}$ e Carlos Ricardo Soccol ${ }^{1}$
}

${ }^{1}$ Departamento de Engenharia de Bioprocessos e Biotecnologia; Universidade Federal do Paraná; 81531-970; Curitiba - PR - Brasil. ${ }^{2}$ Serviço Nacional de Aprendizagem Industrial / SENAI-CIC; Técnico de Ensino Pleno Biotecnologia; 81.310-000; Curitiba - PR - Brasil.

\begin{abstract}
Bacillus thuringiensis var. israelensis (Bti) is one of the most important microrganisms used in bioinsecticide formulations. It has an application against insect vectors of several diseases. Despite his efficiency and environment safety, his use is limited by the production costs. All around the world, research have been performed to discovery materials that reduce the final costs of Bti insecticides. The present paper has tested the application of poultry litter as culture medium to Bacillus thuringiensis var. israelensis. The bioinsecticide was tested against thirty instar Aedes aegypti larvae and the performance has been compared with the waste cassava starch and citrus pulp media. The poultry litter has enabled the higher larvae mortality; it achieved 100\% in 20 and 10mg. $L^{-1}$ concentrations and exceeded 50\% in 5mg. $L^{-1}$. The others materials have got significant lower performances. The waste cassava starch was useful only in 20mg. $L^{-1}$ concentration and falling in others values, and the citrus pulp medium has not reached $50 \%$ of larvae mortality even in the higher concentration $\left(20 \mathrm{mg} . \mathrm{L}^{-1}\right)$. The chemical composition of poultry litter revealed the presence of $39 \%$ of nitrogen source and $4 \%$ of carbon source, beyond the higher concentrations of potassium and phosphorus.
\end{abstract}

Key-words: Culicidae, waste cassava starch, citrus pulp, fermentation medium, bioinsecticide

\section{INTRODUÇÃO}

Presente em diversas partes do globo, os insetos da família Culicidae são responsáveis por uma série de danos e prejuízos à saúde humana. Por praticarem a hematofagia, esses insetos acabam funcionando como vetor de diversos agentes infecciosos, incluindo vírus, protozoários e helmintos. Dessa forma, o combate a esses culicídeos sempre foi considerada uma medida indispensável para o controle dessas doenças (Consoli e Oliveira, 1994). Por várias décadas, os inseticidas químicos ocuparam lugar de destaque nesse trabalho, sendo aplicados para a eliminação

$\overline{\text { Author for correspondence: andremelo101@gmail.com }}$ surgimento de resistência dos insetos. Além disso, foram observados efeitos tóxicos da utilização desses produtos no ambiente (Braga et al., 2004).

Nesse contexto, a descoberta de bactérias produtoras de endotoxina com efeito entomopatogênico abriu uma nova perspectiva ao desenvolvimento de inseticidas e combate dos insetos vetores. A utilização desses bioinseticidas apresenta a vantagem de maior especificidade ao organismo alvo e, consequentemente, sendo ambientalmente seguros, não acumulando na cadeia trófica (Kumar et al., 2000). O Bacillus thuringiensis é uma bactéria gram positiva de crescimento aeróbico, cujo cristal protéico apresenta uma grande toxicidade aos organismos 
alvo, isto é, culicídeos, coleópteros, lepidópteros, himenópteros ou nematódeos, dependendo da subespécie de $B$. thuringiensis.

O Bacillus thuringiensis var. israelensis (Bti) é a subespécie mais amplamente utilizada nos programas de controle de dengue e febre amarela. Apresentam duas categorias de cristais, as proteínas Cry e Cyt, que apresentam uma elevada afinidade com larvas de Aedes aegypti. Uma vez ingeridas pela larva, os cristais são solubilizados e ativam células do trato digestivo, provocando lise seguida de morte da larva (Polanczyk et. al., 2003). Encontrado no solo naturalmente, o isolamento desse microrganismo pode ser realizado através de técnicas simples, com meios seletivos, sendo realizado rotineiramente para o estudo de novas cepas patogênicas da bactéria (Ootani et. al., 2011).

Apesar do elevado potencial entomopatogênico do cristal protéico do $\mathrm{Bti}$, o microrganismo não possui grandes exigências fisiológicas para produzi-los e multiplicar-se em larga escala. Uma fonte comum de carbono e nitrogênio, além de uma aeração adequada, é suficiente para produção de biomassa e toxinas de Bti (Dulmage et al., 1990). Entretanto, a escolha da composição do meio de cultivo é de suma importância na produção do bioinseticida. $\mathrm{O}$ meio padrão para o microrganismo é composto por substâncias sintéticas de alto valor agregado, elevando excessivamente o custo final do produto e inviabilizando sua produção. Sendo assim, a pesquisa por matérias-primas de baixo custo tem sido um desafio nas fermentações com Bacillus thuringiensis var. israelensis.

A utilização de resíduos agrícolas tem sido bastante estudada para a produção de inseticidas biológicos. Diversos trabalhos já demonstraram o potencial existente nos subprodutos à base de soja, aveia, amendoim, trigo, feijão, entre outros (Melo et. al., 2009; Prabakaran \& Balaraman, 2006; Zouarin et. al., 2002; Ejiofor e Okafor, 1989). Tal prática se mostra eficiente na redução de custos, mas sua aplicação só tem efeito a nível local, usando matérias-primas disponíveis em cada região (Dulmage et al., 1990).

Outra vertente dos trabalhos com fermentação de bioinseticidas utiliza resíduos em decomposição como matéria-prima para os meios de cultivo. Considerando a grande quantidade de matéria orgânica presente, os estudos com lodo foram iniciados. O material resultante de estações de tratamento se mostrou eficiente nas fermentações da bactéria, com produção de grande quantidade de células e ação entomopatogênica (Montiel et al., 2001). Apesar da necessidade de um prétratamento que neutralize e habilite o lodo para as fermentações, os autores obtiveram uma redução significante nos custos com as fontes de carbono e nitrogênio.

Seguindo essa linha, a cama de frango, resíduo rico em matéria orgânica proveniente de aviários, tem demonstrado um grande potencial como base de meios de cultivo. Trabalhos recentes trazem resultados satisfatórios de fermentações de Bti com cama de frango quando comparado ao meio padrão para a bactéria (Poopathi \& Abidha, 2007). Apesar da grande disponibilidade desse material e da necessidade de produção de bioinseticidas de Bti, não existem estudos que verifiquem a aplicabilidade desse resíduo de aviários utilizando uma cepa de Bti nativa no Brasil.

$O$ presente trabalho visou testar a utilização da cama de frango na fermentação de Bacillus thuringiensis var. israelensis e comparar o desempenho de mortalidade de larvas ao resultado produzido a partir da fermentação com outros resíduos agrícolas, tais como bagaço de mandioca e a polpa cítrica. A cama de frango também foi analisada quimicamente para determinação da composição do substrato.

\section{MATERIAIS E MÉTODOS Microrganismo}

A cepa de Bacillus thuringiensis var. israelensis utilizada foi BR-01, isolada no estado do Paraná e mantida no Laboratório de Processos Biotecnológicos (LPB-1), da Universidade Federal do Paraná (UFPR). O microrganismo foi estocado em nitrogênio líquido a $-40^{\circ} \mathrm{C}$ com solução de glicerol 10\%. Para o preparo dos pré-inóculos, pequenas alíquotas eram fermentadas com o meio LB (Sambrook et al., 1989) e mantidas em freezer $-4^{\circ} \mathrm{C}$.

\section{Cama de frango}

A coleta da cama de frango foi realizada em uma granja de frangos de corte no município de Mandirituba, estado do Paraná. Foram coletas amostras de diferentes pontos de uma cama de frango de terceira geração, isto é, suporte que abrigou a terceira ninhada de animais. O material foi acondicionado em caixas de isopor com tampa vedada, garantido assim um ambiente livre de umidade e entrada de organismos. 


\section{Resíduos agroindustriais}

Foram testados dois resíduos agroindustriais associados à indústria alimentícia com elevado teor nutricional; baixo custo e facilmente disponíveis no Paraná. Empregou-se o bagaço de mandioca, subproduto obtido da fabricação de polvilho, e a polpa cítrica, resíduo resultante da produção industrial de suco de laranja e seus derivados.

\section{Elaboração dos meios e fermentações}

Os meios de cultivo eram formulados com o composto básico testado, isto é, cama de frango, bagaço de mandioca ou polpa cítrica, diluídos em água destilada numa concentração de $40 \mathrm{~g} \cdot \mathrm{L}^{-1}$. Após ajuste do $\mathrm{pH}$ para 7,0, os meios foram esterilizados a $121^{\circ} \mathrm{C}, 1 \mathrm{~atm}$ por 20 minutos.

$\mathrm{O}$ inóculo foi produzido em frasco Erlenmeyer com o meio Luria Bertani (Sambrook et al., 1989) e fermentado em incubadora rotativa a $120 \mathrm{rpm}$ e $30^{\circ} \mathrm{C}$. Após $24 \mathrm{~h}$, um inóculo de 2,0 - 4,0 × $10^{6}$ UFC. $\mathrm{mL}^{-1}$ era adicionado aos meios testados. Os frascos permaneciam incubados por $72 \mathrm{~h}$ e após esse período foram usados nos bioensaios.

\section{Criação de Aedes aegypti}

Os adultos da cepa Rockfeller de Aedes aegypti (Linnaeus) foram criados em gaiolas forradas com telas $(25 \mathrm{~cm} \times 25 \mathrm{~cm})$ e acondicionados no interior de estufa com temperatura de $26-30^{\circ}$ C. A alimentação foi feita com solução de $10 \%$ de sacarose e os repastos sanguíneos ocorriam semanalmente utilizando camundongo neonatos.

A ovoposição foi feita em papéis filtro cortados imersos em recipientes de plástico com água. Os ovos eram separados e protegidos de calor e umidade. Para os bioensaios, os ovos eram mantidos em água destilada onde, posteriormente, ocorriam a eclosão das larvas. Essas eram mantidas em estufa e alimentadas com a ração Alcon (Goldfish).

\section{Bioensaio \\ Utilizou-se o delineamento experimental inteiramente casualizado com três repetições com 20 larvas. As variáveis estudadas foram: tipo de substrato (cama de frango, bagaço de mandioca e polpa cítrica) e concentração aplicada do bioinseticida (20, 10 e $\left.5 \mathrm{mg} . \mathrm{L}^{-1}\right)$. Os testes foram realizados em recipientes de plástico com $10 \mathrm{~cm}$ de altura e $10 \mathrm{~cm}$ de diâmetro, contendo 20 larvas de $3^{\circ}$ instar de A. aegytpi em $90 \mathrm{ml}$ de água. O volume foi completado para $100 \mathrm{ml}$ com a adição de $10 \mathrm{ml}$}

do produto fermentado diluído em água nas concentrações desejadas. Além dos potes que recebiam a solução bacteriana, outros três funcionavam como controle negativo, isto é, sem receber qualquer dosagem do produto. Após $24 \mathrm{~h}$ era feita a análise, com a contagem das larvas vivas. A taxa de mortalidade foi calculada e corrigida com a fórmula de Abbott (1925). Caso fosse observada uma mortalidade superior a $20 \%$ no grupo controle, o bioensaio era invalidado. Para $\mathrm{a}$ análise dos resultados, empregou-se o teste $\mathrm{t}$ Student para cada substrato testado. Todos os tratamentos seguiram um intervalo de confiança de $95 \%, \alpha=0.05$.

\section{Fórmula de Abbott (1925)}

Mortalidade de larvas $(\%)=100 .(\mathrm{X}-\mathrm{Y}) / \mathrm{X}$ $\mathrm{x}=\%$ de larvas vivas no controle; $\mathrm{y}=\%$ de larvas vivas no tratamento

\section{Testes analíticos de composição}

A relação carbono e nitrogênio da cama de frango foi realizada em triplicata através do analisador elementar Flash 2000 da Thermo Scientific. As amostras foram transformadas em um fino pó, após uma secagem de $24 \mathrm{~h}$ a $60{ }^{\circ} \mathrm{C}$ e moídas. Em seguida, eram pesadas em balança analítica específica, entre 2 e $3 \mathrm{mg}$ das amostras e levadas para a análise. Os resultados foram obtidos em porcentagem de cada elemento e a relação $\mathrm{C} / \mathrm{N}$ calculada através da divisão dos teores de $\mathrm{C}$ pelos teores de $\mathrm{N}$.

A quantificação do Fósforo $\left(\mathrm{H}_{2} \mathrm{PO}_{4}{ }^{-}\right)$solúvel em água foi realizada em triplicata pelo método colorimétrico com azul molibdênio, utilizada para solos, plantas e agrotóxicos (Silva, 1999). A determinação do $\mathrm{K}^{+}$solúvel em água foi realizada através do cromatógrafo de íons Compac IC 761 com detector Bioscan 817 da Metrohm. Os resultados foram obtidos em $\mathrm{mg}$ de $\mathrm{K}^{+}$por $\mathrm{ml} \mathrm{de}$ amostra e convertidos em $\mathrm{mg}$ de $\mathrm{K}^{+}$por $\mathrm{g}$ de massa seca do composto.

\section{RESULTADOS E DISCUSSÃO}

Dentre as três formulações testadas, o meio de cultivo composto por cama de frango obteve a maior taxa de mortalidade de larvas (figura 1). Essa composição possibilitou $100 \%$ de eficiência nas duas primeiras diluições (20 e $\left.10 \mathrm{mg} . \mathrm{L}^{-1}\right)$, alcançando $55 \%$ na concentração de $5 \mathrm{mg} . \mathrm{L}^{-1}$. Esse resultado foi significativamente maior que $o$ 
obtido pelo meio com bagaço de mandioca, que teve $100 \%$ em $20 \mathrm{mg} . \mathrm{L}^{-1}, 65 \%$ em $10 \mathrm{mg} . \mathrm{L}^{-1}$ e $20 \%$ em 5mg.L $\mathrm{L}^{-1}$. Quando comparado com o produto de polpa cítrica, que obteve 30 e $14 \%$ nas diluições de 20 e $10 \mathrm{mg} . \mathrm{L}^{-1}$, respectivamente, além de não ter eficiência na concentração de $5 \mathrm{mg} \cdot \mathrm{L}^{-1}$.

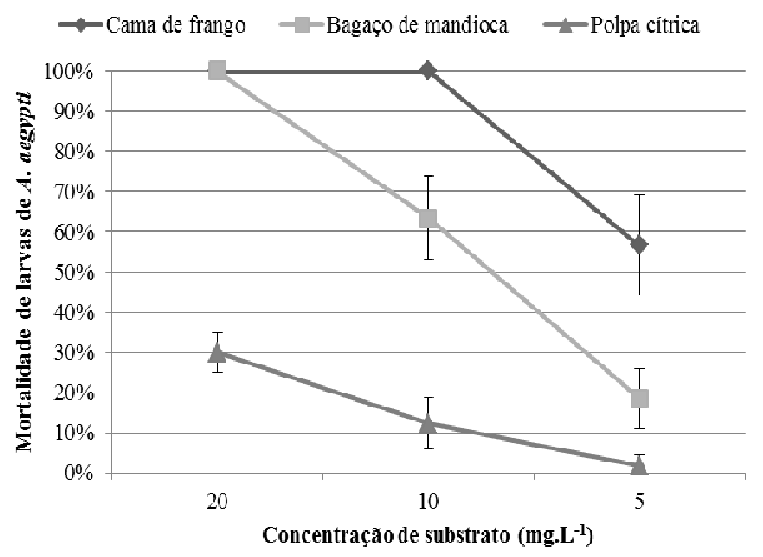

Figura 1- Porcentagem de mortalidade de larvas L3 de Aedes aegypti produzida pelas diferentes formulações do bioeinseticida de Bacillus thuringiensis var. israelensis Berliner (Bti) após 24 horas.

Quantitativamente, a cama de frango apresentou elevadas taxas de carbono, obtendo $39,61 \%$ da composição, revelando-se uma rica fonte desse nutriente (Tabela 1). Compostos nitrogenados também se fazem presentes, mas dessa vez em menor quantidade, representando $4,00 \%$ da composição final. Outros nutrientes verificados em uma taxa elevada foram os sais, sobretudo potássio e fósforo, ingredientes não tão usados rotineiramente na composição de meios de cultivo bacteriano.

Tabela 1. Composição química de cama de frango

\begin{tabular}{ll}
\hline & Média \\
\hline Nitrogênio (\%) & 4,00 \\
Carbono (\%) & 39,61 \\
Relação C/N & 9,9 \\
Potássio mg.g ${ }^{-1}$ de peso seco & 17,23 \\
Fósforo mg.g $\mathrm{g}^{-1}$ de peso seco & 1,31 \\
\hline
\end{tabular}

Dentre os meios testados, a composição que recebeu polpa cítrica propiciou uma menor mortalidade de larvas, indicando menor sucesso na fermentação. Segundo Rodrigues et al. (2011), a polpa cítrica é um substrato complexo com teores consideráveis de nitrogênio e, principalmente, carbono. Sua utilização mostrou-se eficiente como substrato e suporte para fermentações no estado sólido para fungos do gênero Aspergillus e Fusarium. Por outro lado, a quantidade de carbono descrita para polpa cítrica foi inferior ao obtido com a cama de frango, 19 e $39 \%$, respectivamente. Essa diferença pode ter sido determinante para o sucesso da fermentação e produção de cristal protéico com a cama de frango, pois, quanto à fonte de nitrogênio, os dois substratos disponibilizam quantidades muito semelhantes, 4\% na cama de frango e 5\% na polpa cítrica.

Quanto ao meio de cultivo com bagaço de mandioca, o resultado inferior na fermentação do Bti não pode ser explicado pelo baixo teor de carbono disponível no meio. Esse substrato disponibiliza, inclusive, uma quantidade ainda maior desse nutriente, $65 \%$ contra $39 \%$ obtida na cama de frango. Contudo, o decréscimo na eficiência do bioinseticida provavelmente foi influenciado pela baixa quantidade de nitrogênio presente, resultando numa fermentação menos produtiva ao observado com o meio de cama de frango. $\mathrm{O}$ bagaço de mandioca disponibiliza apenas $0,24 \%$ desse nutriente essencial (Vandenberghe et al., 2000).

$\mathrm{O}$ resultado de mortalidade propiciado pelo meio de cultivo com a cama de frango indicou uma multiplicação bacteriana satisfatória e consequente elevada produção de endotoxina, quando comparado às demais formulações testadas. Dentre os motivos para tal diferença, a composição dos meios de cultivo pareceu ser determinante. A utilização desse substrato tem se mostrado bastante propícia ao crescimento bacteriano devido ao balanço existente entre as fontes de carbono e nitrogênio. Na cama de frango podemos encontrar uma grande variedade de compostos orgânicos, provenientes dos restos alimentares das aves e do seu próprio metabolismo (Savitha et al., 2007). Esse complexo meio de cultivo, contendo elevados teores de fibras, queratinas e proteínas insolúveis, pareceu favorecer a multiplicação e produção de toxinas entomopatogênicas.

O bom desempenho nos bioensaios laboratoriais com Aedes aegypti indica a viabilidade da utilização da cama de frango como substrato para a produção do Bacillus thuringiensis var. israelensis, cepa BR-01. Esse desempenho poderia ter sido ainda mais elevado com um tratamento prévio do substrato, como verificaram Ozcana et al. (2010), que se utilizaram de hidrólises ácidas para pré-tratar o material. Tais resultados atestam 
o potencial da cama de frango no cultivo do Bti e potencial desse substrato na formulação de um bioinseticida.

\section{CONCLUSÃO}

A cama de frango pode ser usada para a produção do bioinseticida de Bacillus thuringiensis var. israelensis, cepa BR-01, com elevada entomopatogenicidade a Aedes aegypti, sendo superior ao obtido com o produto produzido com bagaço de mandioca e polpa cítrica.

\section{RESUMO}

O Bacillus thuringiensis var. israelensis (Bti) é um dos principais microrganismos utilizados na formulação de bioinseticidas, possuindo grande aplicação no combate a insetos vetores de diversas doenças humanas. Apesar de eficiente e ambientalmente seguro, sua utilização ainda é limitada pelos custos de produção. Em todo mundo, pesquisas têm sido feitas em busca de matériasprimas que reduzam o custo final dos inseticidas de Bti. O presente trabalho testou a aplicação da cama de frango na composição do meio de cultivo para Bacillus thuringiensis var. israelensis. O bioinseticida resultante foi testado contra larvas L3 de Aedes aegypti e teve seu resultado comparado com os bioinseticidas produzidos com bagaço de mandioca e polpa cítrica. O meio com cama de frango possibilitou uma maior mortalidade de larvas, alcançando $100 \%$ nas diluições de 20 e $10 \mathrm{mg} . \mathrm{L}^{-1}$ e ultrapassando $50 \%$ em $5 \mathrm{mg} \cdot \mathrm{L}^{-1}$. Os demais resíduos obtiveram resultados significativamente inferiores. O bagaço de mandioca foi efetivo apenas na diluição de $20 \mathrm{mg} . \mathrm{L}^{-1}$, caindo nas demais concentrações, e a polpa cítrica sequer atingiu $50 \%$ de mortalidade na maior concentração do produto. A composição química da cama de frango revelou a presença de $39 \%$ de fonte de carbono e $4 \%$ de fonte de nitrogênio, além de elevadas concentrações de sais de potássio e fósforo.

Palavras-chave: Culicidae, bagaço de mandioca, polpa cítrica, meio de fermentação, bioinseticida

\section{REFERÊNCIAS}

Abbott, W. S. (1925), A method of computing the effectiveness of an insecticide. Journal of Economic Entomology, 18, 265-267.

Braga, I. A.; Lima, J. B. P.; Soares, S. S.; Valle, D. (2004), Aedes aegypti Resistance to Temephos during 2001 in Several Municipalities in the States of Rio de Janeiro, Sergipe, and Alagoas, Brazil. Memórias do Instituto Oswaldo Cruz, Rio de Janeiro, 2, 199-203.
Consoli, R. A. G. B. e Oliveira, R. L. (1994), Principais mosquitos de importância sanitária no Brasil. Rio de Janeiro: Fiocruz. 225p.

Dulmage, H. T.; Yousten, A. A.; Singer, S.; Lacey, L. A.; Lawrence, A. (1990), Guidelines for production of Bacillus thuringiensis $\mathrm{H}-14$ and Bacillus sphaericus. WHO, Geneva.

Ejiofor, A. O.; Okafor, N. (1989), Production of mosquito larvicidal Bacillus thuringiensis serotype H-14 on raw material media from Nigeria. Journal of Applied Microbiology, 67, 5-9.

Kumar, A.; Sra K.; Sangodkar, U. M. X.; Sharna, V. P. (2000), Advances in the bio-control of mosquito vector utilizing Bacillus sphaericus and B. thuringiensis var. israelensis. Proceeding of the Natural Academy of Sciences India. 70,1-20.

Melo, A. L. A; Soccol, C. R.; Thomaz-Soccol, V.; Nogueira Jr., M. (2009), Evaluation of Bacillus sphaericus bioinseticide produced with white soybean meal as culture medium for the control of Culex (Culex) quinquefasciatus. Cad Saúde Pública, Rio de Janeiro, 25, 561-569.

Montiel, M. L. T.; Tyagi, R. D.; Valero, J.R. (2001), Wastewater treatment sludge as a raw material for the production of Bacillus thuringiensis based biopesticides. Water Research, 35, 3807-3816.

Ootani, M. A.; Ramos, A. C. C.; Azevedo, E. B.; Garcia, B. O.; Santos, S. F.; Aguiar, R. W. S. (2011), Avaliação da toxicidade de estirpes de Bacillus thuringiensis para Aedes aegypti Linneus, (Díptera: Culicidae). Journal of Biotechnology and Biodiversity, 2, 37-43.

Ozcana, O.; Icgenb, G.; Ozcengliz, G. (2010), Pretreatment of poultry litter improves Bacillus thuringiensis-based biopesticides production. Bioresource Technology. 101, 2401-2404.

Polanczyr, R. A.; Garcia, M. O.; Alves, S. B. (2003), Potencial de Bacillus thuringiensis israelensis Berliner no controle de Aedes aegypti. Rev. Saúde Pública, São Paulo, 37, 813-816.

Poopathi, S.; Abidha, S. (2007), Use of featherbased culture media for the production of 
mosquitocidal bacteria. Biological Control, 43, 4955.

Prabakaran, G.; Balakaran, K (2006), Development of a cost-effective medium for the large scale production of Bacillus thuringiensis var israelensis. Biological Control, 36, 288-292.

Rodrigues, C.; Rossi, S. C.; Spier, M. R.; Vandenberghe, L. P; Soccol, V. T.; Soccol, C. R. (2011), Citric pulp and sub-products of citric juice industry used as substracts in bioprocesses. In: Carlos Ricardo Soccol, Ashok Pandey, Vanete Thomaz Soccol, Christian Larroche. (Org.). Advances in bioprocesses in food industry. $1^{\mathrm{a}} \mathrm{Ed}$. New Delhi: Asiatech Publishers Inc. 1, 121-135.

Sambrook, J.; Fritsch, E. F.; Maniatis, T. (1989), Molecular Cloning. A Laboratory Manual. 2 ed. Cold Spring Harbor: Cold Spring Harbor Laboratory Press.

Savitha, G. J.; Teiashwini, M. M.; Revati, N.; Sridevi, R.; Roma, D. (2007), Isolation, Identification and Characterization of a Feather Degrading Bacterium. International Journal of Poultry Science. 6, 689-693.

Silva, F. C. (1999), Manual de análises químicas de solos, plantas e fertilizantes. Brasília: Embrapa.

Vandenberghe, L. P. S.; Soccol, C. R.; Pandey, A.; Lebeault, J. M. (2000), Solid-state fermentation for the synthesis of citric acid Aspergillus niger. Bioresource Technology. 74, 175-178.

Zouari, N.; Achour, O.; Jaoua, S. (2002), Production of delta-endotoxin by Bacillus thuringiensis subsp kurstaki and overcoming of catabolite repression by using highly concentrated gruel and fish meal media in 2- and 20-dm3 fermenters. Journal of Chemical Technology and Biotechnology. 77, 877-882. 